The Journal of Animal \& Plant Sciences, 31(1): 2021, Page: 1-18

ISSN (print): 1018-7081; ISSN (online): 2309-8694

Review Paper

\title{
INSIGHTS ON THE NORTH CHINA LEOPARD (PANTHERA PARDUS JAPONENSIS GRAY, 1862): CHALLENGES IN DISTRIBUTION, POPULATION STATUS, THREATS, AND IMPLICATIONS FOR CONSERVATION
}

\author{
K. Vitekere ${ }^{1,2} ;$ K. Tulizo ${ }^{1}$, M. Zaman ${ }^{1} ;$ H. Karanja ${ }^{1,3} ;$ Y. Hua ${ }^{4 *}$ and G. Jiang ${ }^{1 *}$ \\ ${ }^{1}$ College of Wildlife and Protected Areas, Northeast Forestry University,26, Hexing Road, Xiangfang District, \\ Heilongjiang Province 150040 Harbin, China. \\ ${ }^{2}$ Tayna Center for Conservation Biology- Kasugho University of Nature Conservation and Development, Goma, D.R.C \\ ${ }^{3}$ Department of Natural Resources, Egerton University P.O. Box 536-20115 Egerton, Kenya. \\ ${ }^{4}$ Guangdong Provincial Key Laboratory of Silviculture, Protection and Utilization, Guangdong Academy of Forestry, \\ Guangzhou 510520, China. \\ *Corresponding author's email: jgshun@126.com; wildlife530@hotmail.com
}

\begin{abstract}
China has four sub-species of leopard throughout the country. One of them is the North China leopard (Panthera pardus japonensis, Gray, 1862) which experiences a wide range of threats. It remains at the centre of interest for recent research and new management policies within its natural habitat. Due to limited studies for a long time, its current distribution, and population size remain vague without accurate information. Using existing literature, we synthesized information on this endemic and endangered subspecies. We used research engines such as Google scholar, Baidu and China National Knowledge Internet (CNKI) to find any available literature about the sub-species. By reviewing 39 published documents, nine national and international web news, and asking questions to some specialists in leopard and wildlife managers; we have concluded that the species' current distribution has drastically changed, only $2 \%$ of its historical distribution remains occupied by around 174-348 individuals. Extant patches are in continual danger as the Proximity Index previously found was small. Habitat fragmentation, retaliation, and decline in prey species are the main threats. However, there is hope for its survival, since the mega project launched in 2015 "Bring Leopards Home" and new management policies are being undertaken in protected areas that will annihilate or reduce threats. In addition, many researchers or governmental organisations are currently carrying out studies on this sub-species. These studies will fill information gaps on the North China leopard based on scientific evidence.
\end{abstract}

Keywords: Conservation and management; distribution; habitat ranges; North China leopard; patch; sub-species; threats. https://doi.org/10.36899/JAPS.2021.1.0187

Published online August 26, 2020

\section{INTRODUCTION}

The leopard (Panthera pardus) is the most widespread carnivore species (Nowell and Jackson, 1995; Perez et al., 2006; Jacobson et al., 2016). It has nine subspecies (Miththapala et al., 1996; Uphyrkina et al., 2001), and is genuine predator (Hayward et al., 2007). Leopard is found in diverse ecosystems such as forests, desert landscapes, meadows, and alpine areas (Nowell and Jackson, 1996; Sung, 1998; Smith and Xie, 2008; Minqi, 2018). Leopard populations extend across much of Africa, and Asia (Sung, 1998). It is distributed from the Middle East to the Pacific coasts (Nowell and Jackson, 1996; Sunquist and Sunquist, 2017) and considered to be a species with high plasticity behaviour for habitat challenges. Nonetheless, although the leopard has adaptation quality, many sub-species population have recorded a drastic decline (Nowell and Jackson, 1995; Stein and Hayssen, 2013; Wang et al., 2016). The African sub-species for example, have become extinct in almost one-third of its historic habitat (Ray et al., 2005) and Asian sub-species have shown an abrupt population reduction (Ario et al., 2008; Jackson and Nowell, 2008; Kittle and Watson, 2008; Mallon et al., 2008). Accordingly, Asian sub-species have either the status of Endangered or Critically Endangered species on the International Union for the Conservation of Nature (IUCN) Red List (Laguardia et al., 2015).

Leopards exert real effects on biological communities through diverse mechanisms, and their impacts on population structure is often great (Noss et al., 1996; Treves and Karanth, 2003; Estes et al., 2011; Williams et al., 2017; Farris et al., 2017; Han et al., 2019). They are key species in trophic chain (Ripple et al., 2014), they increase the resilience of ecosystems within different landscapes (Tittensor et al., 2014) and stabilise the prey populations by predation and their interspecific competition are the basis of species' dynamics (Bruner et al., 2001). Unfortunately, for a long time these species worldwide have been marginalised due to diverse 
pressures involved between them and human, in terms of regular competition. In Asia, one of the most cited anthropogenic threats is the economic boom during the previous decades (Sears, 2018). This induced many direct and indirect threats on ecosystems such as forest degradation, decrease of animal species, proliferation of human-wildlife conflict becoming the basis of hunting leopards (Breitenmoser et al., 2010; Athreya et al., 2016). Combined with carnivore furtive behaviour, these threats make leopards the least understood of all mammals (Nowell and Jackson, 1996; MacDonald and Loveridge, 2010; Rodgers and Janečka, 2013; Sunquist and Sunquist, 2017) and challenge their conservation management plans (Linkie et al., 2006; Ford, 2017).

Due to the reduction in suitable habitat in Asia, leopard populations have become extirpated from HongKong, Singapore, Kuwait and Syria (Stein et al., 2016). Particularly, the Indo-chinese sub-species ( $P$. pardus delacouri, Pocock, 1930) is extirpated in Singapore, probably in Laos and Vietnam, nearly extirpated in Cambodia and China, and has a greatly reduced distribution in Malaysia, Myanmar and Thailand (RostroGarcía et al., 2016). Yet, one Asian landscape that is considered to be the richest temperate forest in the world in term of biodiversity, is the Hengduan Mountains area, located in China (MacKinnon, 2002), and China contains a high rate $(14.7 \%)$ of the world's wild mammals (Grumbine, 2007). Even having significant biodiversity in this large country, wildlife has undergone threats. Hence scientists need a coordinated determination to understand the drivers of biodiversity loss and their impact on sustainable management of natural resources. Since 1998, the government has improved biodiversity conservation and sustainable management policies in Protected Areas throughout the whole country (Xu et al., 2009; Wei et al., 2014).

Among nine sub-species of leopard, China has four: P.p. Orientalis; P.p. fusca; P.p. japonensis and P.p. delacouri (Minqi, 2018), which are distributed in different landscapes throughout the whole country in the past, except in high altitude western region and the Gobi desert (Laguardia et al., 2015; Jianjun et al., 2018). The presence of P.p. delacouri is still doubtful in China (Laguardia et al., 2015; Song, 2019). According to recent studies in China, as time passes, the leopard's range thins, Ran and Chen (2002) stressed that the major part of the remaining habitat is reportedly no longer fitting species' conditions and local extirpations have followed within several regions across the leopard's ranges. Thus in 2010, Chinese leopards sub-species (P.p. Orientalis; P.p. fusca; P.p. japonensis and P.p. delacouri) were denoted in 19 provinces (Bao et al., 2010), while five years later they were encountered in only 11 provinces of the country (Laguardia et al., 2015). In a recent past, these Chinese sub-species were less studied, yet, since the 2000s studies have emerged bringing out some different findings related to them.

North China leopard (NCL), an endangered and endemic sub-species to China, is still short of suitable and scientific information and science-based approaches for its management. The NCL was intermittently declared to be threatened for diverse reasons (Shoemaker, 1993; Nowell et al., 2016; Wildfact News, 2017), without reliable population estimates and information on problematic individuals which are responsible of conflict when an interaction with local people occurred. Even with hope of this sub-species' current viability in natural habitat when adapted management strategies are implemented, there are few areas (provinces in China) sheltering the species that have regular monitoring programs such as Shanxi (with governmental organizations) and most of the remaining provinces still have a knowledge gap because of no accurate census data or long-term viability estimates of this sub-species. The lack of in-depth studies on endangered species has always been perceived as a shortage of conservation attention and focus (Jacobson et al., 2016). Referring to all these settings, the development and the implementation of genuine and comprehensive management and conservation policies for this sub-species is a tough task for governmental agencies, ecologists, and conservationists.

Thus more attention and new approaches of sustainable management are crucial since, firstly, its population is no longer as large as it can be assumed, and secondly, the long term survival of this leopard remains under debate in some habitats (Laguardia et al., 2015). By reviewing the literature, we discussed the distribution, conservations insights, threats and human-leopard conflicts and implications for management of the NCL in China as it remains a threatened sub-species and needs to be more thoroughly documented to enhance its protection.

\section{MATERIALS AND METHODS}

A comprehensive and systematic review of scientific, secondary and internet-based literature on the NCL was carried out. Published articles were compiled using research engines: Google Scholar, Baidu, and China National Knowledge Internet (CNKI). We used keywords "North China leopard", "Chinese leopard", "Panthera pardus japonensis" or a single word from these grouping words in Google Scholar; and "华北豹 (Huá béi bào)" which means "North China leopard" both in Baidu and CNKI. Baidu led us to Chinese news links when CNKI allowed finding Chinese published articles. We didn't use a limited data since we presumed there would be a scarcity of peer-reviewed articles on this subspecies. We also searched for international news and 
asked questions to some specialists of leopard and wildlife managers.

From the literature content, compiled documents were categorized in three predefined kinds referring to previous studies (e.g. Jacobson et al., 2016): (1) applied (with topic addressing in this review: distribution, threats, conservation status and implication for sustainable management), (2) fundamental (with information pertaining to ecology such as site use, interaction, niche partitioning, diet, etc.), (3) documental (any article referring on the NCL), which could be aimed to study another species or topic but it has some information on the NCL. Some Chinese articles have English abstracts, which help us to have an overall idea about the content before being explored.

Three patches metrics (the Patch Size Index, the Core Area Index, and the Proximity Index) were the most important in the interpretation of species distribution about landscape structure and patch characteristics. They were computed with FRAGSTATS. The Patch Size Index (PSI) is the measure of the relative size of a single patch; it is the percentage of the total historic extent comprised by the largest patch. A larger value indicates greater dominance of a single patch. The Core Area Index (CAI) portrays the core area of a range kind as a percentage of the entire extent of that kind; a larger Core Area Index indicates a greater amount of core habitat. The Proximity Index (PI) represents the value depicting the degree of isolation and fragmentation; a larger value indicates greater proximity to nearby patches and/or more of the corresponding patch type within the search radius. We analysed these patches metrics indices according to values found in the previous study (e.g. Jacobson et al., 2016).

\section{RESULTS}

Overview of explored literature: We documented 17 applied articles (plus one conference article in English) which constituted 25.5\%; 8 fundamental articles (plus one edited book: $19.2 \%) ; 13$ documental articles (27.2\%) and $9 \mathrm{Web}$ News (site webs or TV constituted 17\%). The total depicts lesser domination of articles written in Chinese than those in English (Fig.1). Documentation on the NCL started many years ago, the earliest studies were conducted by Shoemaker $(1978 ; 1983)$ on NCL in captivity; but most of the articles are from the 2000s, and we found a total of 39 documents (Table 1) published on the NCL, categorized according to their content. Five articles were found with studies done in the distribution area of the NCL and using only the word "leopard" without precision of subspecies, they were excluded for two reasons: (1) lack of confirmation if it was NCL; (2) most of them were only focused on presence, and since we found an article confirming the NCL's presence in those areas, it was not necessary to include them.
Review outline: Results were synthesized in a thematic shape that permits us to structure and to comprehend the quintessence of literature found. The draft distinguishes three essential and interconnected topics portraying the current situation of NCL (Fig. 2). We have (1) distribution (Historic vs current distribution and the differentiation of the sub-species); (2) threats (conflicts with human, prey depletion, habitat loss and hunting); (3) Conservation (research conducted on NCL, in situ conservation and ex situ conservation) and the underlying sustainable policy management.

\section{Distribution}

Historic extent vs current distribution: The NCL is the most widespread in China amongst the four leopard subspecies present in this country (Laguardia et al., 2015; Song, 2019). Nevertheless, referring to its historical distribution, the sub-species has lost almost $98 \%$ of its original known range (Jacobson et al., 2016; Fig. 3). The presence of this sub-species was confirmed in eight provinces based on a scientific camera traps study (Laguardia et al., 2015): Hebei, Shanxi, Shaanxi, Henan and Sichuan, contain sustainable populations; Ningxia, Qinghai, and Tibet contain in most cases, sparsely distributed individuals in isolated Protected Areas, and their long term survival remains under debate (Mongabay news, 2017; Jianjun et al., 2018). Provinces of Guizhou, Fujian and Zhejiang are potentially occupied, but with the probability of already been extirpated in the last two provinces (Laguardia et al., 2015).

The most densely populated habitat of NCL is found in the Taihang Mountains within the Shanxi Province (Li, 2016; Yuli, 2018) and the Ziwuling forest region in Shaanxi Province, where 28 individuals were recorded (Minqi, 2018). The largest and most continuous habitat is the expanse Shaanxi-Gansu-Ningxia-Qinling (Song, 2019). Other mountains like Luliang, Liupan, Zhongtiao and Taiyue also host the sub-species (WilfFact News, 2017). According to Jacobson et al. (2016), the current occupied area is extended on $68,000 \mathrm{~km}^{2}$.

The real historic range distribution of this subspecies has drastically decreased due to multidimensional aspects of threats caused to its habitat. The remaining populations are usually present in small and isolated areas. Their presence in mountain regions (Shanxi-HebeiHenan-Shaanxi provinces), where there is thin human population, contribute to maintain the survival of this sub-species (Li, 2016; Zhou, 2017) and could sometimes enter the towns as recently documented in Pingquan (Hebei province) by a farmer's domestic surveillance camera (CCTV, 2019; HLJTV, 2019).

The sub-species differentiation issues: Once a subspecies bears a country's name, it would be easier to be distinguished from other sub-species within the same species. But the NCL may lose its distinctiveness when it 
Table 1. List in of publications $(n=39)$ with a focus on North China Leopard, beginning from the most recent.

\begin{tabular}{|c|c|c|c|c|}
\hline No & Authors and Year & Title & Journal & Category \\
\hline 01 & Han et al. (2019) & $\begin{array}{l}\text { Comparison of the fecal microbiota of two free-ranging } \\
\text { Chinese sub-species of the leopard (Panthera pardus) using } \\
\text { high-throughput sequencing }\end{array}$ & PeerJ & Documental \\
\hline 02 & Xiaomin (2019) & $\begin{array}{l}\text { Assessment on Habitat Suitability for Panthera pardus } \\
\text { fontanierii in Tieqiao Mountain Nature Reserve Based on } \\
\text { Maxent Model }\end{array}$ & Shanxi Forestry Science and Technology & Fundamental \\
\hline 03 & Song (2019) & North Chinese Leopard: China's surviving forest kings* & Forest and Humankind & Applied \\
\hline 04 & Yuelong (2019) & $\begin{array}{l}\text { Two leopard prints are not the same. How to identify the North } \\
\text { Chinese Leopard* }\end{array}$ & Forest and Humankind & Fundamental \\
\hline 05 & $\begin{array}{l}\text { Song and Yuelong } \\
(2019)\end{array}$ & The Wilderness of the North Chinese Leopard* & Forest and Humankind & Applied \\
\hline 06 & Wei et al. (2019) & The abundance of the North Chinese Leopard in captivity* & Dynamic & Applied \\
\hline 07 & Minqi (2018) & North Chinese Leopard: Growing Quietly in Ziwuling * & $\begin{array}{l}\text { China Academic Journal Electronic } \\
\text { Publishing }\end{array}$ & Applied \\
\hline 08 & Yuli (2018) & $\begin{array}{l}\text { Population Quantity Investigation of Panthera Pardus } \\
\text { Fontanierii of Tieqiao Mountain in Shanxi }{ }^{*}\end{array}$ & Shanxi Forestry Science and Technology & Applied \\
\hline 09 & Jianjun et al. (2018) & Breeding of captive North Chinese Leopard ${ }^{*}$ & $\begin{array}{l}\text { Journal of Henan Forestry Science and } \\
\text { Technology }\end{array}$ & Documental \\
\hline 10 & Song (2018) & We will go together with them* & Forest and Humankind & Fundamental \\
\hline 11 & Sears (2018) & Leopards in China: the wild card & Journal of Creative Sustainability & Documental \\
\hline 12 & Zhou (2017) & $\begin{array}{l}\text { A Suitability and Connectivity Analysis of North Chinese } \\
\text { Leopard }\end{array}$ & Asia Lambert Conformal Conic ${ }^{* *}$ & Applied \\
\hline 13 & Laguardia et al. (2015) & $\begin{array}{l}\text { The current distribution and status of leopards Panthera pardus } \\
\text { in China }\end{array}$ & Oryx & Applied \\
\hline 14 & Song (2016) & Discovery of the North Chinese Leopard by Infrared Camera* & Forest and Humankind & Applied \\
\hline 15 & Stein et al. (2016) & Panthera pardus. The IUCN Red List of Threatened Species & Gland, Switzerland: IUCN & Documental \\
\hline 16 & $\mathrm{Li}(2016)$ & $\begin{array}{l}\text { Rare North Chinese Leopard sits on Taihang Mountains } \\
\text { waiting for a road back to Beijing* }\end{array}$ & Beijing Science and Technology News & Applied \\
\hline 17 & Jacobson et al. (2016) & $\begin{array}{l}\text { Leopard (Panthera pardus) status, distribution, and the } \\
\text { research efforts across its range }\end{array}$ & PeerJ & Applied \\
\hline 18 & Song (2015) & North Chinese Leopard in Taihang Mountain* & Forest and Humankind & Applied \\
\hline 19 & Song (2014) & $\begin{array}{l}\text { Using camera trap to monitor a North Chinese leopard } \\
\text { (Panthera pardus japonensis) population and their main } \\
\text { ungulate prey }{ }^{*}\end{array}$ & Biodiversity Science & Applied \\
\hline 20 & Dou et al. (2014) & $\begin{array}{l}\text { The complete mitochondrial genome of the North Chinese } \\
\text { Leopard (Panthera pardus japonensis). }\end{array}$ & Mitochondrial DNA Part A, & Documental \\
\hline 21 & Hayssen & Panthera pardus (Carnivora: Felidae) & Mammalian Species & Fundamental \\
\hline
\end{tabular}




\begin{tabular}{|c|c|c|c|c|}
\hline & $(2013)$ & & & \\
\hline 22 & Hou (2012) & Leopard found in Jiaozuo* & Jiaozuo Yearbook & Applied \\
\hline 23 & Song (2012) & North Chinese Leopard lives only in China* & Forest and Humankind & Applied \\
\hline 24 & Changle et al. (2009) & Checking the distribution of Leopard in Fujian Province & Forestry Science and Technology & Documental \\
\hline 25 & Wang et al. (2008) & $\begin{array}{l}\text { Resources status and protection of Panthera pardus in } \\
\text { Taihangshan Mountain National Reserve, Jiyuan, China* }\end{array}$ & $\begin{array}{l}\text { Journal of Henan Forestry Science and } \\
\text { Technology }\end{array}$ & Fundamental \\
\hline 26 & Smith, and Xie, (2008). & A Guide to the Mammals of China, & Princeton University Press ${ }^{* *}$ & Fundamental \\
\hline 27 & Liu et al. (2007a) & $\begin{array}{l}\text { Surviving Status of Leopard (Panthera pardus) in Gansu } \\
\text { Province* }\end{array}$ & Sichuan Journal of Zoology & Fundamental \\
\hline 28 & Liu et al. (2007b) & $\begin{array}{l}\text { The distribution of Leopard (Panthera pardus) in Zhejiang } \\
\text { Province* }\end{array}$ & $\begin{array}{l}\text { Special Wild Economic Animal and Plant } \\
\text { Research }\end{array}$ & Documental \\
\hline 29 & Gao et al. (2007). & $\begin{array}{l}\text { An investigation of Leopards in Liupan Mountain Nature } \\
\text { Reserve }^{*}\end{array}$ & Forest Resource Management & Documental \\
\hline 30 & Ran and Chen (2002) & The wild leopard and its protection in Guizhou province* & Guizhou Forestry Science and Technology & Documental \\
\hline 31 & Uphyrkina et al. (2001) & $\begin{array}{l}\text { Phylogenetics, genome diversity and origin of modern leopard, } \\
\text { Panthera pardus }\end{array}$ & Molecular Ecology & Documental \\
\hline 32 & Chunping et al. (2001) & $\begin{array}{l}\text { Status and conservation of the wild resources of the leopard in } \\
\text { Henan Province* }\end{array}$ & $\begin{array}{l}\text { Journal of Henan Forestry Science and } \\
\text { Technology }\end{array}$ & Applied \\
\hline 33 & Sung 1998 & China red data book of endangered animals & Science Press, Beijing & Applied \\
\hline 34 & $\begin{array}{l}\text { Nowell and Jackson } \\
(1996)\end{array}$ & Wild Cats: Status Survey and Conservation Action Plan & Cat Specialist Group ${ }^{* *}$ & Documental \\
\hline 35 & Miththapala et al. (1996) & $\begin{array}{l}\text { Phylogeographic sub-species recognition in leopards (Panthera } \\
\text { pardus): molecular genetic variation }\end{array}$ & Conservation Biology & Fundamental \\
\hline 36 & $\begin{array}{l}\text { Nowell and Jackson } \\
(1995)\end{array}$ & New Red List Categories for Wild Cats. & Cat News & Fundamental \\
\hline 37 & Shoemaker (1983) & $\begin{array}{l}\text { Population dynamics of pedigree leopards, Panthera pardus } \\
\text { ssp, in captivity. }\end{array}$ & Zoo Biology & Applied \\
\hline 38 & Shoemaker (1978) & Status of rare leopards in captivity. & Carnivore & Documental \\
\hline 39 & Gray (1862) & Description of some New Species of Mammalia & $\begin{array}{l}\text { Proceedings of the Zoological Society of } \\
\text { London }\end{array}$ & Fundamental \\
\hline
\end{tabular}


is being subsumed by its neighbour from the northern part of the country, the Amur leopard. The following terms: bedfordi, chinensis, grayi, hanensis and fontanierii were used as a synonym to japonensis (Smith and Xie, 2008; Stein and Hayssen, 2013). Some Chinese studies still use P. pardus fontanierii when referring to the NCL (e.g. Yuli, 2018; Xiaomin, 2019). In the past, the eastern and southern China leopards were classified as fontanierii, along with the current NCL populations of Hebei, Beijing, Shanxi and Shaanxi (Song, 2019). In other southern parts, the NCL was considered as P. p. delacouri (Smith and Xie, 2008), even though Uphyrkina et al. (2001) thought that population could be P. p. fusca. The distribution in China of delacouri and japonensis is not controversial, but there are many ambiguities in the outlining of the existing areas of these sub-species (Song, 2019).

In addition, the NCL's distribution range is in the south of Amur leopard (distributed in north China). Due to the absence of a biogeographical barrier between these two sub-species (Jacobson et al., 2016; Kitchener et al., 2017), the Cat Classification Task Force of the IUCN Cat Specialist Group recently revised the classification of the NCL. They subsumed japonensis to orientalis (Han et al., 2019; CGTN News, 2019), although the NCL was earlier labelled as the typical sub-species in Northern regions of China since 1862 (Allen, 1938; Gray, 1862). Nonetheless, these subspecies' taxonomy must be based on molecular evidence. Genetic evidences should be the basis to clear up the difference between NCL and both the sub-species of the Tibet population (Laguardia et al., 2015) and the Amur leopard which despite their habitats overlap, these two felines are different by body characteristics (CGTN News; 2019).

Main threat drivers: For a long time, the NCL was threatened by a wide range of anthropogenic pressures. The major threats for this sub-species as it seems to be common to other carnivores, include human-wildlife conflicts, prey decrease, the loss and degradation of habitat, and hunting/poaching. The combination of all these threats contributed significantly to NCL extirpation in some regions and in others they are still challenging NCL's management efforts.

Leopards interacting with human activities: There are four causes of these interactions, which always lead to human-wildlife conflicts that the NCL has undergone in its current habitats. There are two categories: (1) leopard preying on livestock, which is the most human-carnivore conflict documented (Shoemaker, 1993; Nowell et al., 2016); (2) activities encroachment (Vitekere et al., 2020; Hua et al., 2020). In 2015 in the Heshun County (Shanxi), leopards preyed on farmers' cattle, and 48 cows were killed where over 5,000 cows live. At that time, an adult cow was estimated to $10,000 ¥(\$ 1,449)$, which is almost the annual income of a local inhabitant. In 2016, a single village lost 50 yaks preyed on by leopards in Ganzi
(Sichuan Province), but there has never been the retaliatory case in Ganzi because Tibetan ethnic people have a Buddhism-based benevolent culture. Unless these cases continue without any resolution, this slight quietness in this region will probably change (Mongabay News, 2017).

The activities overlap occurs when humans are searching for arable lands or pasturage for herds and leopards are hunting as it has a carnivorous diet, and for them wide hunting ranges are required (Hayward et al., 2007; Vitekere et al., 2020). The two uncommon interactions are summarised by creating fear to human and direct attacks of humans by carnivores, which have never been motioned in Shanxi province (Song and Yuelong, 2019) contrarily to its neighbour, the Shaanxi province which has recorded human attacks (Sohu News, 2006).

Hunting and poaching: During 1950s, the NCL was killed because it was considered to be a sort of dangerous pest and for the trade of parts; $3500 \mathrm{~kg}$ of its bones from Shanxi were sold in 1960s, and in the 1970s $2447 \mathrm{~kg}$ were purchased (Sung, 1998). In the 1980s, 33 specimens with details of location and time were killed. Except for leopard's parts being traded for traditional culture and use in Chinese medicine (Sung, 1998; Li et al., 2013), yet the Chinese government has already forbidden the use of leopard products used in medicine, such as leopard balm, and other individuals were killed without a specific reason. Until the beginning of the 1980s, hunting was legal in China (Alexander et al., 2016). Nowadays, this practice still threatens wildlife and not only ungulates are hunted or poached, but even the NCL, an apex predator (that may be considered as dangerous for human) is undergoing hunting (Dou et al., 2014; Jacbson et al., 2016).

Three provinces were cited with a high rate of NCL hunting. Firstly in Shanxi and Hebei, leopards appear as a main livestock threat. Therefore, local people undertake retaliatory measures for defending their livestock herds (Shoemaker, 1993; Nowell et al., 2016; Wildfact News, 2017) and the main method used was the NCL hunting. Secondly, within the Henan province, a kill of eight leopards was noted from 1999 to 2007 (Wang et al., 2008) which constitute a significant loss for rare species.

Habitat loss and fragmentation: Currently, the NCL in some regions is reduced to small, isolated and terribly imperiled populations in patches due to habitat loss and degradation (Dou et al., 2014). The principal cause is the exceptional Chinese socioeconomic growth and development changes over the past 20 years (Smith and Xie, 2008; Riordan and Shi, 2016). This factor caused the loss of leopard habitat; on the one hand by converting landscapes in agriculture lands (Nowell and Jackson, 1996; Laguardia et al., 2015; Jacobson et al., 2016) given 
that China has the largest population worldwide and the feeding needs increased abruptly (Grumbine, 2007; Xu et al., 2009). On the other hand, the industrial development and infrastructure construction, which not only has led to habitat loss but the cases of leopards crushed by trucks were reported (Mongabay News, 2017). Pertaining to patch metrics computed by Jacobson et al. (2016), the NCL had 0.4 as the Patch Size Index, 51.3 as the Core Area Index and 1.6 as Proximity Index, with a total of 13 extant patches. It is obvious (Fig. 3) that a large part of the historical distribution of this sub-species had been considerably reduced to small isolated patches with seven potential patches.

Prey decrease: The prey depletion is actually challenging the survival of the NCL (Laguardia et al., 2015; Nowell et al., 2016; Wildfact News, 2017) in some of its landscapes. It often comes from the hunting of ungulate species by local people for both livelihood and trade of animal parts (Mallon et al., 2007). In addition to hunting, habitat loss affects ungulate abundance in degraded ecosystems. However, Song et al. (2014) found that wild boar (Sus scrofa) and roe deer (Capreolus pygargus) were the main prey species of NCL with respective densities of 3.48 and 3.61 individuals $/ \mathrm{km}^{2}$ in Qingcheng forest. With a normal threshold of 0.5 prey individual $/ \mathrm{km}$ for a big cat, their findings depicted high prey abundance only in this area, when elsewhere the prey species' scarcity is signaled. This factor is important since the leopard has a carnivorous diet; its life in patches depends on the availability of enough prey species. Thus the lack in prey abundance leads to livestock depredation on local inhabitants' herds. We recall that one of the key reasons for NCL population reconstitution in many of its isolated ranges is the prey population increasing especially the wild boar and hare (Lepus sp) (Wang et al., 2008; Hou, 2012). Wide range and abundant prey are two key factors for the conservation of the NCL population in China (Song, 2019).

\section{Conservation and improvement of management strategies:}

State of research focused on the North China leopard: The NCL suffers from a shortage of studies which brings to the lack of knowledge of this sub-species. With only four peer-reviewed English articles found in "applied article category", the documentation remains rudimentary. Lately, the Shanxi Provincial Forestry Bureau (SPFB) has invited academics to study leopard populations in certain parts of the province. Thus the China Felids Conservation Alliance (CFCA) a governmental organisation has conducted studies in Shanxi using camera traps since the year 2008 (Chinadaily News, 2016). Later, researchers of another governmental grass-root organisation established in 2011, the Wocheng Institute of Ecology and Environment (WIEE), used the same methodology in a much bigger landscape to monitor the NCL and wildlife in general (Mongabay News, 2017). In addition, China set up a special research centre in Beijing Normal University to carry out research and protect the NCL (Chinadaily News, 2016). The Feline Research Center of the Chinese State Forestry Administration of the Northeast Forestry University is implementing research on this sub-species.

In situ conservation status and habitat restoration: Currently most of the NCL population is concentrated within approximately 22 Nature Reserves most situated in Taihang Mountains and some close regions (Sohu News, 2003; Song et al., 2014), despite a dense network of Protected Areas in China (Ministry of Environment Protection of the People's Republic of China, 2011). With an estimated population in the whole country of 174-348 leopards (confirmed cases of 92-183 individuals) the density is assessed to be from one to two individuals for every $100 \mathrm{~km}^{2}$ (Laguardia et al., 2015) or 0.6 to 3.5 individual by $100 \mathrm{~km}^{2}$ with a low encounter rates for signs of $0.1 \mathrm{sign} / \mathrm{km}$ in Shanxi (Laguardia, 2015). The potentially occupied sites included, the population would increase (estimated numbers above could be validated). Some years ago, ( $\sim 10$ years previous to Laguardia et al., (2015) the NCL population was estimated to be around 1500 individuals in the wild (Gao et al., 2007; Liu et al., 2007). In 2001, the Taihang Mountains had 40-68 leopards (Chunping et al., 2001) and in the 1960s, the NCL density changed drastically from $1 / 86 \mathrm{~km}^{2}$ to $1 / 122 \mathrm{~km}^{2}$, but only Shanxi Province had 100 individuals in the 1990s (Sung, 1998). Nowadays the NCL is present in 13 patches with a high rate of isolation (according to the core area index value of 1.6).

Great investments have been made to restore $87,000 \mathrm{~km}^{2}$ and to create real corridors in the area of Taihang Mountains-Shanxi-Beijing-Henan-Shaanxi. The project is named "Bring Leopards Home", and the initial goal has been achieved as the project raised $400,000 ¥$ (USD 58,526). The aim is to reduce patches isolation, to expand the suitable habitat, and restore the carrying capacity of the connected landscape. This is a habitat restoration strategy in Protected Areas management where policies are being improved in Nature Reserves hosting the NCL. An example is the Taihang Mountains region where CFCA set up a ranger team composed by local people for patrolling the area monthly to check camera traps and clear illegal hunting snares, as well as for evaluating livestock losses caused by leopards (Li, 2016). Accordingly, the compensation mechanism has been established for livestock depredation, in Ganzi and Heshun County supported by CFCA where the program pays only partial compensation for livestock lost to leopards: $2,000 ¥(\$ 290)$ for an adult cow and 1,000 yuan $(\$ 145)$ for a calf and these expenses changed across years (Fig 4). In the same area, the Heshun government 
did a readjustment of a project to construct a wind power project. The project was for a $100 \mathrm{~km}$ long road right through leopard habitat, and if it was built the habitat would be greatly affected (Mongabay News, 2017).

Nowadays, this sub-species is listed under the Appendix I of the Convention on International Trade of Endangered Species of Wild Fauna and Flora (CITES) (Uphyrkina et al., 2001; Dou et al., 2014; Li, 2016) and classified as endangered sub-species on the IUCN Red List (Nowell and Jackson, 1995, 1996; Li, 2016). China has already considered Panthera pardus as Critically Endangered on the China Species List database, and it is a Class I protected species (Lu et al., 2010; Wang and Xie, 2004; Li, 2016). Based on the actual situation of the NCL (threats, population number, distribution ranges), Laguardia et al. (2015) recommended updating this subspecies classification to Critical Endangered on the IUCN Red List.

Ex-situ conservation: Ex-situ conservation is a complementary technique to in situ conservation which consists of conserving the biological diversity outside natural habitat, targeting all levels of biodiversity such as genetic, species, and ecosystems (Balcombe, 2009; Getachew, 2012). The NCL has undergone this kind of conservation, and referring to the studbook of the species by Columbus Riverbed Zoo of South Carolina, in 1985 USA had 105 specimens of the NCL (52 males and 53 females) in 42 different zoos (Sung, 1998). The Zoological Park of Columbia had the NCL among four sub-species of leopard (with Amur leopard, Persian leopard and Ceylon leopard) and this sub-species was revealed to be the most common pedigree maintained in captivity. However, the NCL suffered from the ill effects of inbreeding due to their small population size. The issue was solved as further individuals were brought from Omaha zoo in Nebraska, totaling nine (three males and six females) which had no genealogy link from other captive individuals (Shoemaker, 1983).

In Europe, the Leipzig Zoological Park in early 1953 received specimens of the NCL. After this importation, individuals have been very prolific in captivity, with over 330 individuals (Shoemaker, 1978). In mid-1960s and early 1970s the NCL presented an overpopulation in several European zoos and even for private holders; thus reproduction was curtailed. More recently, however, after the main breeders died or ceased breeding because of advancing age and previous reproduction reduction, there has been a decline in both captive propagations and overall numbers (Shoemaker, 1983). Yet, France registered three births of cubs within this decade. The Paris Zoological Park had a birth of two cubs on November 2009; the female was from the Berlin Zoo and the male from the Salzburg Zoo (NBC News, 2009). A second zoo, the Paris Jardin des Plantes zoo announced the birth of a cub on May 2017. The zoo borrowed the cub's parents from the Czech Republic and Poland in 2012 as part of a European exchange program between Zoos. While there are thought to be just 2,500 individuals of the sub-species worldwide, the new baby was only the third to be born across the world in 2017 (Konbini News, 2017).

The NCL is widespread in many zoos including Chinese zoos (Sung, 1998) such as Zhengzhou Zoo (Jianjun et al., 2018), Taiyuan zoo (Wei et al., 2018) with eight specimens, the first arrived in the zoo in December 2001 (Chengcheng unpubl. data) and further worldwide zoos such as Henry Doorly Zoo, Royal Zoological Society of Antwerp, San Diego Zoo (Uphirkina et al., 2001), Tierpark zoo in Berlin, Toronto Metropolitan Zoo, etc.

\section{DISCUSSION}

Distribution and identification: Accurate approximations of distribution both in the historical and current context for animal species require much more research to support the asserted assumptions. While research and studies are necessary to predict and clear up ecological perceptions (Durant et al., 2007), there is a completely obvious change from long term data on the historical and existing ranges in the distribution of NCL's populations. The core population was near Beijing (Lagurdia et al., 2015; Li, 2016; Mobgabay News, 2017) and had spread into surrounding landscapes, in northern and central China (Dou et al., 2014; Han et al., 2019).

According to Jacobson et al. (2016), the human density is high in the historic range distribution compared to the extant landscape of NCL. The human population density effect would be either a direct or indirect predictor among extirpation causes of this sub-species (Zhou, 2017; Song, 2019). A recent study revealed that human settlements were the principal factors for the habitat selection of NCL in Shanxi (Xiaomin, 2019). Although Woodroffe (2000) also found a significant relationship between human density and leopard extinction, the leopards have a high rate of plasticity, which allows them to withstand critical conditions of human overcrowding. They were found close to big crowded cities such as Mumbai (Odden et al., 2014), Johannesburg (Kuhn, 2014), and Nairobi (Jacobson et al., 2016).The highest human density is 958 people $/ \mathrm{km}^{2}$ in extant leopard areas, thus the most important factor to leopard survival is appropriate management policy, population tolerance, and suitable habitat with availability of prey (Linnell, et al., 2001; Chapron et al., 2014; Athreya et al., 2015). Yet Grumbine (2007) agree that the human overpopulation threatens biodiversity in China.

Specificity, especially for endemic species as the NCL should be mentioned. The restriction of their populations in a closed area with only one country's 
conservation policies, ecosystems and human perception may increase their vulnerability to extinction (Jacobson et al., 2016). Indeed, the precise species population number is undetermined (Song, 2019), and its real distribution remains under debate as there was no evident data in regions with potential presence of the NCL, and regions with a probability of extirpation revealed the species' presence.

One of the principal criteria of describing a species' distribution pertains to its identification which should separate the species from members within the same guild and pedigree (Pocock, 1930; Avise and Ball, 1990; O'Brien and Mayr, 1991; Farhadinia et al., 2015). The Cat Classification Task Force of the IUCN Cat Specialist Group, the empowered organization in carnivore classification, should review once again and produce an accurate classification of the $P$. p. japonensis. In the north part of the distribution, the subsumption of P.p. japonensis to P.p. orientalis supports the probability that the mainland Asian sub-species had a major mixing, and there was lack of solid boundaries (Uphyrkina et al., 2002). The same scenario was witnessed in the south of its distribution area, where the NCL was considered as $P$. pardus delacouri (Smith and Xie, 2008) and Uphyrkina et al. (2001) assumed that the population could be $P$. pardus fusca even if the NCL is separated to the South China leopard by the Yangtze River (Chunping et al., 2001; Jacobson et al., 2016). Moreover, rivers as a boundary are not real ecological limits for leopards, but they can somewhat pose barriers to the big cat (Cozzi et al., 2013).

Due to their widespread distribution, secretive characteristics, and plasticity for habitat, leopards are difficult to categorize accurately as different sub-species (Stein et al., 2016). It is a little confusing to precisely define the real distribution and identification of the subspecies because the evolutionary pressures that have pried them away from their ancestral are still at work. If time and nature are permitting, these sub-species themselves could one day become unique leopard species.

Major threats: There are peculiarities of threats in each landscape. Four significant threats for NCL are all interconnected. Often the first two (human-carnivore conflicts and hunting/ poaching) are correlated and the other two threats (habitat degradation and the prey decrease) are also correlated. The human-carnivore battle is a common issue, and this is due to leopards' proteinrich diet (Treves and Karanth, 2003). Species undergo a high risk since in many landscapes of the NCL, no matter whether livestock off-take due to leopards is low, they may become victims even when there was attack by other carnivores, specifically if poisoning is used as leopards will scavenge their prey (Myers, 1976; Islam et al., 2014). Some herders knew the NCL's habit of coming back to eat unfinished prey in Heshun County, and a few leopards have died of poisoning in this area (Mobgabay News, 2017).

For example in findings of Li et al. (2013) and Alexander et al. (2015) herders stated that livestock depredation was the greatest and most common issue affecting their livestock, compared with other natural causes (disasters or disease), in seven villages in the Qilianshan National Nature Reserve, Gansu Province, where another species of leopards (Snow Leopard) was preying on herds. This is the main reason for retaliation against the NCL in Shanxi and Hebei (Shoemaker, 1993; Nowell et al., 2016) as herders must protect their livestock, which in most cases even when losses are few it represents a significant challenge for villagers whose principal or the only source of incomes for households is livestock (Dickman, 2010). Therefore an enmity was created between leopards and cattle breeders. Due to the large home range needed by leopards; they can be dragged into repeated competition with non-cattlebreeder residents who are only farmers but rather with similar needs for small game (Treves and Karanth, 2003). In such cases, the hunting of leopards is always signaled. Sometimes big carnivores are hunted by wire snares, which make them unable to cause fear towards humans (Jacobson et al., 2016; Standaert, 2018). The NCL was mostly hunted and poached in past years principally for animal products, which were precious merchandise for animal traders and in some cultural ceremony (Sung, 1998; Li et al., 2013). However, Shoemaker (1993) found that the fur trade impacted this sub-species less than others, and unfortunately, this did not relieve it from dramatically declining. Some Asian markets had leopards as the most commonly traded big cat species (Oswell, 2010). Raza et al. (2012) documented a huge volume of up to 18,000 leopard claws seized in one operation in Khaga, Uttar Pradesh, India. The NCL is prone to various kinds of clashes with local population beings as an outcome of diverse, overlapping benefits or antipredator campaigns, but several studies demonstrated that killing "problematic specimens" is not a solution for alleviating conflicts.

The second pair of threats (loss of habitat and prey depletion) has played a great role in the NCL's extinction in some regions (Zhou, 2017; Mongabay News, 2017) since the species lost the majority of its historical distribution ranges (Jacobson et al., 2016). The Chinese economic boom had a considerable impact to the forest and reduced the NCL's range to only 20 isolated ranges (13 confirmed and 7 potential, Fig. 3) within the whole country. However, despite forest reduction from development activities, China still has $14.7 \%$ of the world's wild mammals (Grumbine, 2007) and the richest temperate forest in the world in term of biodiversity is the Hengduan Mountains area (MacKinnon, 2002).

Referring to Jacobson et al. (2016) a minimal value found of Patch Size Index for NCL's ranges denotes 
the smallest proportion of remaining ranges in a single patch. It shows that any of the 13 patches found hosting the NCL is not dominated by size which is dangerous for this sub-species' conservation. The sub-species had a small Proximity Index showing the greatest isolation. The fragmentation of remaining extant habitat patches denotes the absence of connectivity between patches (Yuli, 2018). This index is crucial because isolation of a group threatens individuals as they can't move to the next patch when the landscape is facing a menace, which increases animals' vulnerability (Laguardia et al., 2015). Thus with small values for both Patch Size Index and Proximity Index, the NCL is threatened as all its patches are small isolated ranges. Conversely, the NCL had a larger Core Area Index; it depicts the characteristics for the majority of the patches as being the source or essential habitat for the species, yet the importance of connectivity remains vital. Ultimately, these patch metrics brought more precisions on the quality of remaining range distribution of the sub-species which had been degraded and destructed, that lead to an actual average of at least $2 \%$ of NCL historical area now being occupied. Nonetheless, these estimates may be a little exaggerated, but have never been contradicted by any other study (Song, 2019).

At this end, Henle et al. (2004) suggest an indepth study of habitat effect on species in their patches to clarify the impact of habitat loss and fragmentation on wildlife for endangered species. The leopard's prey could not be spared from habitat loss and fragmentation. Loss of prey is one of the key drivers of NCL range contraction (Laguardia et al., 2015; Nowell et al., 2016; Yuli, 2018). Much of the remaining species' habitat has reduced the carrying capacity due to habitat disturbance and the depletion of prey populations. Although prey scarcity is always cited as one of the most severe threats for the NCL, only external causes of this scarcity seem to be studied. Unfortunately internal ones which are linked to the predator-prey interactions remains unstudied. Therefore, when native prey is scarce, carnivores must feed on livestock. Currently, hunting is not legal in China; three decades ago, the situation was not the same (Alexander et al., 2016). This activity contributed largely to prey depletion in habitats as local people were harvesting game without any restriction. Hunting of ungulates for food or trophies can significantly depress wild prey numbers throughout the ecosystems, with a disadvantage for wild carnivores.

Conservation status and implications of sustainable management in the NCL's ranges: Practical actions of species conservation are based on a scientific foundation through research (Sung, 1998; Sutherland et al., 2004). Although there has been a recent interest in NCL studies, the majority is from Chinese literature (27) written in mandarin. Two recent articles (English) trying to describe the NCL distribution were found: Laguardia et al. (2015) and Jacobson et al. (2016).Yet, the first focused on four Chinese sub-species and the second focused on all nine sub-species worldwide. With the published documents found $(n=39)$, applied documents (English $n=4$; Chinese $\mathrm{n}=12$ plus one book), the gap in the research on NCL is obvious, particularly on the conservation status, population, and implications for suitable management policies.

From comparisons with another Panthera genus in China, the Snow Leopard, Alexander et al. (2016) found many studies focused on this species $(\mathrm{n}=106$; with applied articles $n=33$ ), so efforts must be made. While leopard research has increased in China, study efforts were mostly focused on the sub-species with the greatest remaining range whereas sub-species that needed serious care were ignored. For endangered sub-species such as NCL, this scarcity of studies has always been perceived as a shortage of conservation attention and focus (Jacobson et al., 2016) as successful protection actions and strategies often hinge on empirical research at specific sites (Sutherland et al., 2004; Laguardia et al., 2015). Therefore, the deficiency of empirical field data on distribution status and population has not allowed a range-based population estimate. Indeed, since the 2000s the Taihang Mountains have hosted regular studies on the NCL executed by two governmental organisations (WIEE and CFCA), research centres initiated in Beijing, and studies of researchers from diverse universities, and more accurate findings on this sub-species may emerge. Some articles about genetics were found, which are also important since distribution depends on identification (Pocock, 1930; Avise and Ball, 1990; O'Brien and Mayr, 1991; Farhadinia et al., 2015) thus the differentiation issue would be solved.

For the NCL's conservation, management of Protected Areas are the most appropriate strategy (Song, 2019) as it is known worldwide for all ecosystems (Chape, 2005; Mwakatobe, 2013) since it has been associated with sustainable wildlife management (Steffen et al., 2011). China's recent ecological policies through "The Natural Forests Protection Program" started in 1998 have led to significant enhancement in the size and value of forests (Xu et al., 2009; Wei et al., 2014). Indeed, the NCL has its highest population in nature reserves, which are China's strictest Protected Areas, and their core areas do not permit any human activities (Xu and Melick, 2007; Xie et al., 2014). However, reserves housing the NCL suffer from high isolation, which generates difficulties in studying leopard's migration routes. This issue will end soon since on the one hand, CFCA plans to start using the radio-telemetry tracking in studies for population monitoring (Mongabay News, 2017); and on the other hand to mitigate the effects of patch isolation, the "Bring Leopards Home" megaproject is being implemented. The project aims to create corridors between isolated patches, thus this will allow the repopulation of NCL within the 
surrounding areas of Beijing since historically this subspecies lived in the mountains near this city in the late 1990s. One individual of NCL was captured by cameras at less than $150 \mathrm{~km}$ from Beijing in 2014; therefore the "Bring Leopards Home" project is based to the scenario that the NCL wants to return to its previous patches. This project would increase the NCL's density given that leopard frequency is attributable to habitat productivity (Macdonald and Loveridge, 2010).

To perpetuate this sub-species, the NCL has been kept in Chinese zoos for a long time (Jianjun et al., 2018; Wei et al., 2018; Chencheng unpubl. data), and has been even exported abroad long time ago (Shoemaker, 1983; Sung, 1998). The ex situ conservation doesn't just prevent threats, but also extends leopards' longevity than in natural habitat (12 years in natural habitat and 20 years in captivity). A recent study in Europe concluded that large carnivores have been recovering due to reintroduction (Chapron et al., 2014). Unfortunately we didn't document any case of reintroduction of NCL in natural habitat as recommended by Zhou (2017) and Sung (1998), although it is unlikely that there has never been such a case.

Many incentives of implications for sustainable management policies of NCL are being implemented within different reserves that provide shelter to this subspecies. The government, after being aware of mining threats to ecosystems, introduced a regulation on mining extraction (Jiping, 2010), particularly for coal extraction in Shanxi province which produces almost a quarter of the national coal (Naufal et al., 2010; Bing-Yuan and LiXun, 2014). The compensation mechanism when NCL prey on livestock is now applied (Fig. 5), yet, this compensation is still facing some issues in implementation. Indeed, it is useful to perform an integrative approach, which consists of modifying the current compensation programs and make it linked with preventive measures. Also, investigating the potential for a community self-financed insurance scheme. Things have started to change in the past few years. The NCL has begun to make a slow revival in some parts of the country as a result of China's forest conservation efforts and confiscation of private rifles to stop illegal poaching since 2010s. All cited conservation and management policies certify the viability of the NCL in China and assure that this sub-species will highly benefit from new actions taken for wildlife management in this country. New implications from conservation policies justify the survival of NCL but leopard plasticity is a key factor to mention as Sears (2018) stated: "Surprisingly, the leopard has survived in this heavily industrialized country hostage to its vast human population and severe environmental problems. The survival of leopard in China is a testimony to this cat's remarkable ability to survive in challenging conditions".

Moreover, it is crucial to strictly ban the NCL's hunting and severely punish poachers in accordance with the national laws. Also strengthen the national ex situ conservation programs and cooperate with worldwide zoos in order to undertake the reintroduction of some individuals into their natural habitat and keeping a study book for this sub-species. The implementation of mechanisms to increase prey, even the introduction of non-native prey species maybe done in leopards' ranges to palliate the prey depletion in some patches housing the NCL; yet preliminaries study of feasibility must precede.

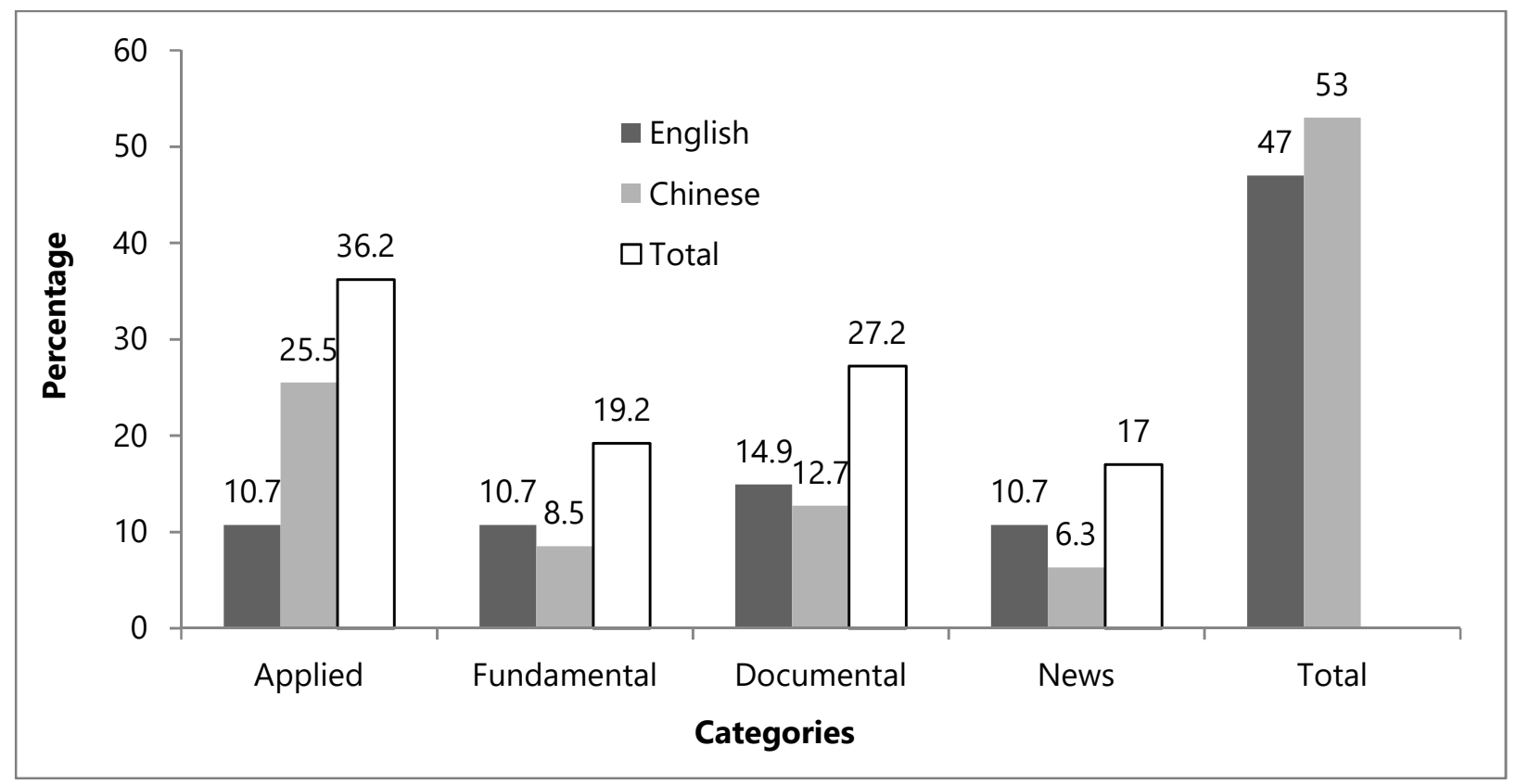

Figure 1. Categories of literature read (including peer-reviewed articles and edited books) 


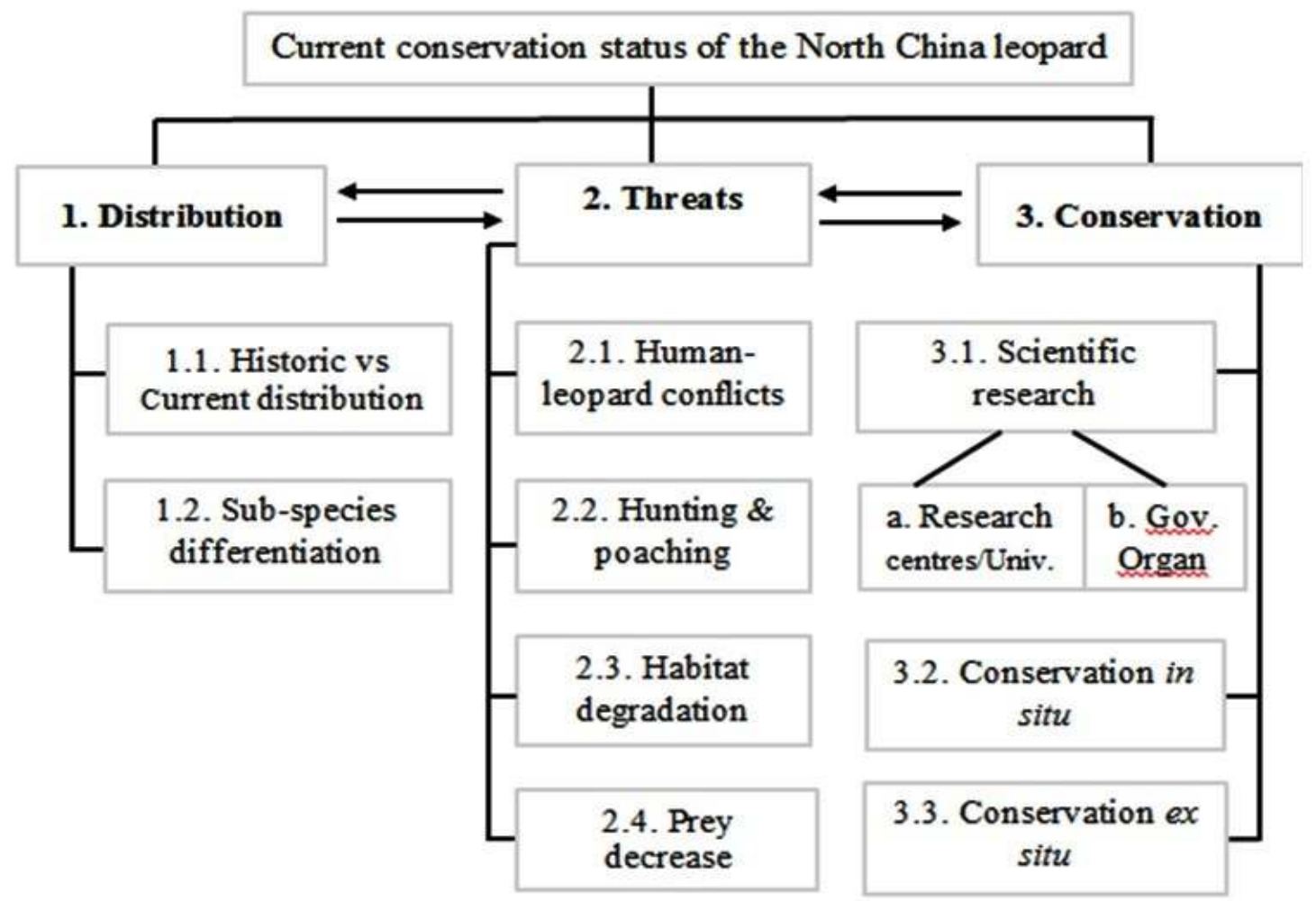

Figure 2. The general scheme patterns for the current status of the North China leopard followed in this review (with Univ.: Universities and Gov. Organ.: Governmental Organisations which intervene in carrying out research on the NCL since recent decade).

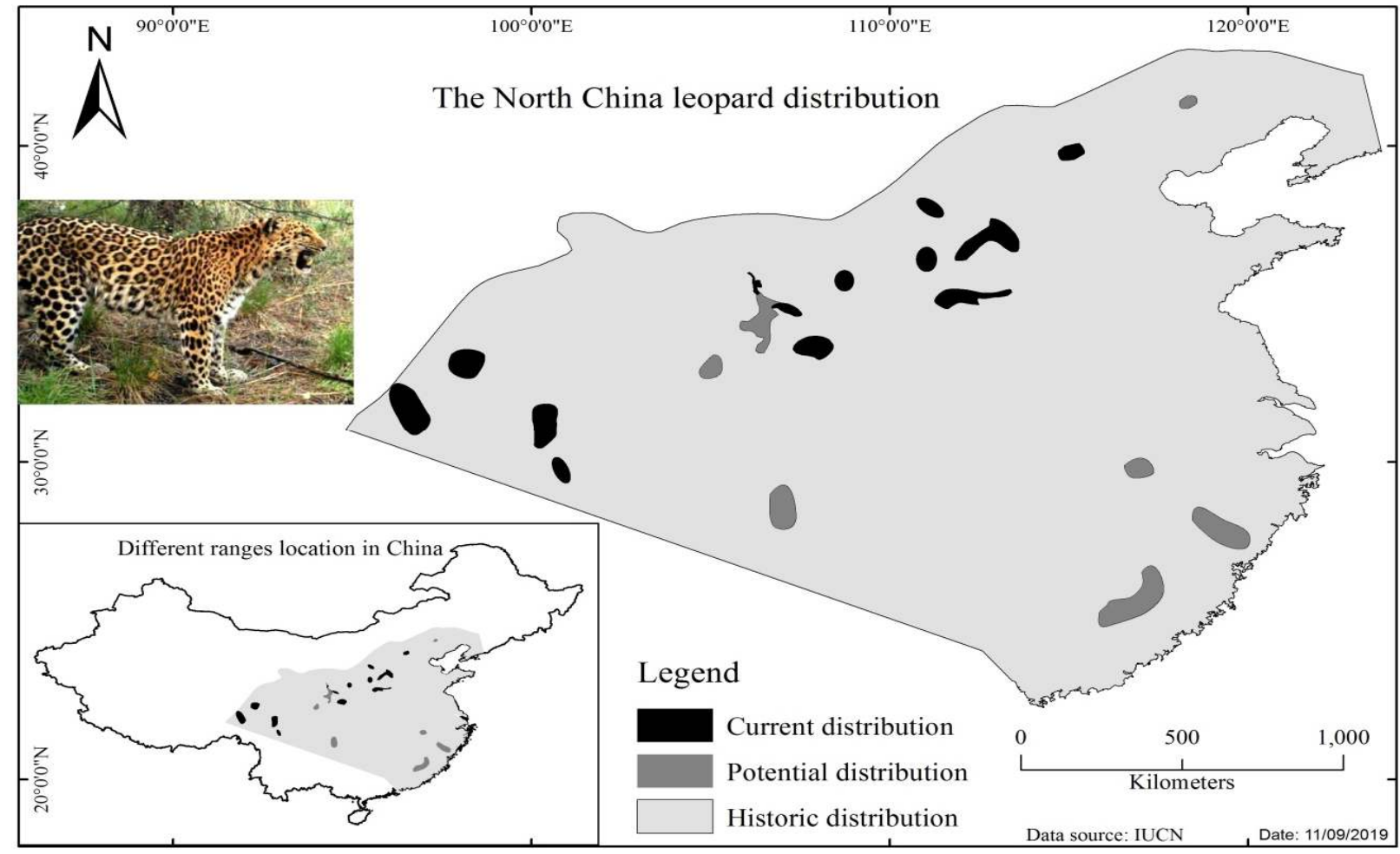

Figure 3. Historic, potential and extant distribution ranges of North China leopard. 


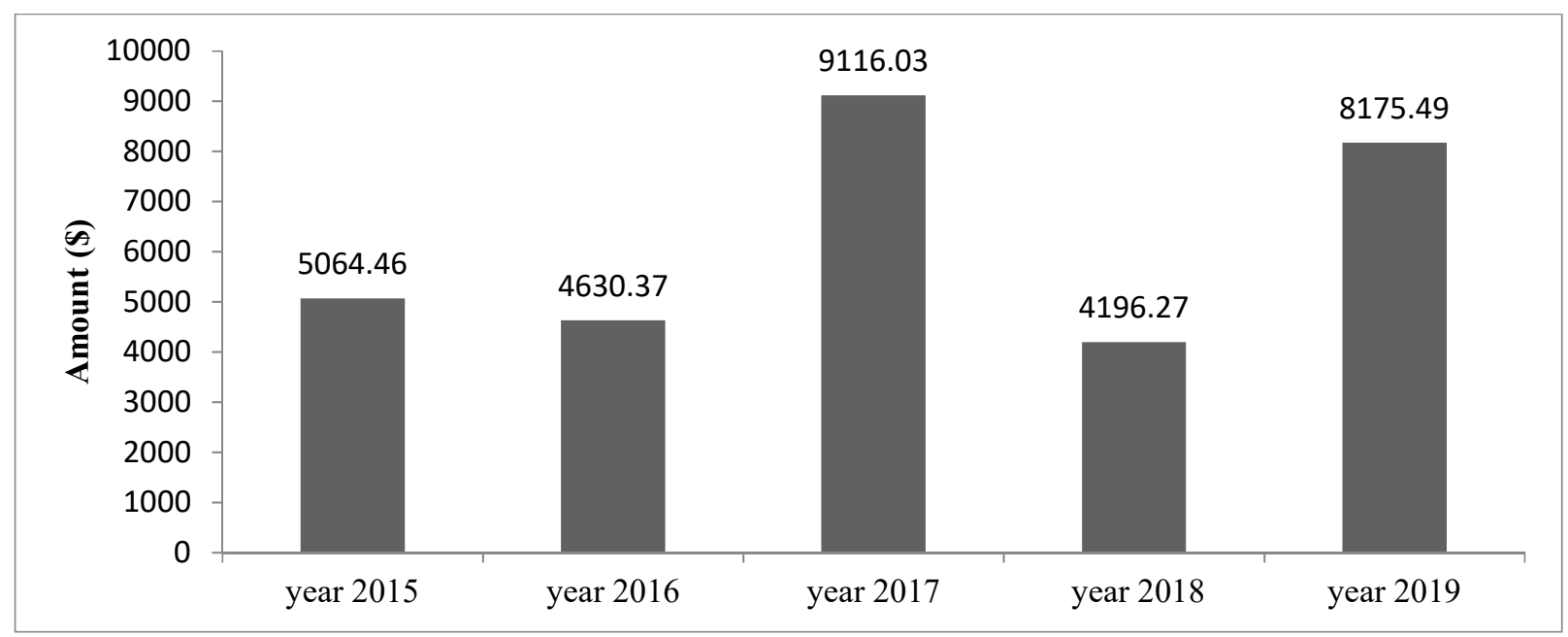

Figure 4. Evolution of expenses of the compensation mechanism for North China leopard preying on livestock in the Heshun County, particularly the Tieqiaoshan Nature Reserve, from 2015 to 2019.

Conclusions: Evident facts are such as only around $2 \%$ of historic distribution ranges of the NCL remain until now. Scientists' view turned in a kind of SOS launched, so many efforts and financial investments were made available to save this sub-species. Positive and hopeful actions are being undertaken within Nature Reserves that cover the current distribution ranges of the NCL. However, threats persist and the most cited are form anthropogenic activities, such as human-carnivore conflicts, hunting and poaching of leopard and the habitat degradation, which depict the reduction of the NCL population (form 1500 individuals in 2007 to around 348 in 2015). Amongst all Chinese sub-species, the North China Leopard is the sub-species with the most magnificent historical distribution ranges in China, but it is also among the least studied. Leopard dynamic population and range size are difficult to estimate due to their secretive nature, the extent of used range, and financial costs involved in monitoring activities. Despite the detailed description of the NCL distribution and credit given to two studies (e.g. Laguardia et al., 2015; Jacobson et al., 2016) both current and historic distribution of NCL may undergo great modifications, although it is unlikely that these are substantial. Their studies focused on the distribution (with others subspecies), while this review focused on conservation, threats and management plan implementation. Information on this sub-species seems to be versatile, so we recommend continual research to always provide upto-date information through new research since successful management often hinges on empirical findings in ecosystems.

Acknowledgements This research is funded by North China Leopard Conservation and Management Project of National Forestry and Grassland Administration, National Key Programmed of Research and Development,
Ministry of Science and Technology (2016YFC0503200), National Natural Science Foundation of China (NSFC 31872241), Fundamental Research Funds for the Central Universities (2572017PZ14). We particularly thank Chengcheng Zhang for providing information, Meadhbh Molloy and Maombi Masinda for multiple corrections.

\section{REFERENCES}

Alexander, J.S., C. Zhang, K. Shi and P. Riordan (2016). A spotlight on snow leopard conservation in China. Integr. Zool. 11(4): 308-321.

Alexander, J., P. Chen, P. Damerell, W. Youkui, J. Hughes, K. Shi and P. Riordan (2015). Humanwildlife conflict involving large carnivores in Qilianshan, China and the minimal paw-print of snow leopards. Biol. Conserv. 187(1): 1-9.

Allen, G.M. (1938). The mammals of China and Mongolia. Publ. Amer. Mus. Nat. Hist., Central Asiatic Exped. 11:1-620.

Ario, A., S., Sunarto and J. Sanderson (2008). Panthera pardus melas. In The IUCN Red List of Threatened Species,http://www.iucnredlist.org [accessed 20 August 2019].

Athreya, V., A. Srivathsa, M. Puri, K.K. Karanth, N.S. Kumar and K.U. Karanth (2015). Spotted in the news: using media reports to examine leopard distribution, depredation, and management practices outside protected areas in Southern India. PLoS ONE 10: e0142647.

Athreya, V., M. Odden, J.D. Linnell, J. Krishnaswamy and K.U. Karanth (2016). A cat among the dogs: leopard Panthera pardus diet in a humandominated landscape in western Maharashtra, India. Oryx 50(1): 156-162.

Avise, J.C. and R.M. Ball (1990). Principles of genealogical concordance in species concepts 
and biological taxonomy. Oxford survey in evolutionary biology 7: 45-67.

Balcombe, J. (2009). Animal pleasure and its moral significance. Appl. Anim. Behav. Sci. 118(3-4): 208-216.

Bao, W., J. Xu, G. Cui and M.R. Frisina (2010). Cat research in China. Cat News Special 5: 7-9.

Bing-yuan, H. and K. Li-Xun (2014). Mine land reclamation and eco-reconstruction in Shanxi Province I: Mine land reclamation model. Sci. World J. 1-9.

Breitenmoser, U., C. Breitenmoser-Wursten, D. Mallon and J.A. Edmonds (2010). Strategy for the Conservation of the Leopard in the Arabian Peninsula. Sharjah: IUCN/SSC Cat Specialist Group, Environment and Protected Areas Authority.

Bruner, A.G., R.E. Gullison, R.E. Rice and G.A. Da Fonseca (2001). Effectiveness of parks in protecting tropical biodiversity. Science 291(5501): 125-128.

CCTV (2019). Hebei Pingquan finds North Chinese Leopard Again: http://www.chinanews.com/sh/shipin/2019/0827/news829155.shtml [Accessed 28 August 2019, in Chinese].

CGTN News (2019). Is the North Chinese leopard getting a new name? https://news.cgtn.com/news/3d3d674e3463544f 34457a6333566d54/index.html [accessed 20 August 2019].

Chainadaily News (2016). Researchers find habitats of North China leopards: http:/www.chinadaily.com.cn/a/201806/06/WS 5b179963a31001b82571e7c6.html [accessed 20 August 2019].

Changle, L., Z. Qi, G. Hu, H. Chunlei and L. Weishi (2009) Checking the distribution of Leopard in Fujian Province. Forest. Sc. Technol. 4(2): 3537. [In Chinese].

Chape, S., J. Harrison, M. Spalding and I. Lysenko (2005). Measuring the extent and effectiveness of protected areas as an indicator for meeting global biodiversity targets. Philos. Trans. R. Soc. Lond., B, Biol. Sci. 360(1454): 443-455.

Chapron, G., P. Kaczensky, J.D.C. Linnell, M. Von Arx, D. Huber, H. Andren, J. V. Lopez-Bao, M. Adamec, F. Alvares, O. Anders and L. Balčiauskas (2014). Recovery of large carnivores in Europe's modern humandominated landscapes. Science 346(6216): 1517-1519.

Chunping, W., L. Jiping, F. Baohua, Q.J. She, G. Guoxuan, Z. Quanlai. L. Chunxia and X. Xinjie (2001). Status and conservation of the wild resources of the leopard in Henan Province. J. Hen. For. Sci. Tech. 21(3): 9-11. [In Chinese].

Cozzi, G., F. Broekhuis, J.W. McNutt and B. Schmid (2013). Comparison of the effects of artificial and natural barriers on large African carnivores: implications for interspecific relationships and connectivity. J. Anim. Ecol. 82(3): 707-715.

Dickman, A.J. (2010). Complexities of conflict: the importance of considering social factors for effectively resolving human-wildlife conflict. Anim. Conserv. 13(5):458-466.

Dou, H., L. Feng, W. Xiao and T. Wang (2014). The complete mitochondrial genome of the North Chinese Leopard (Panthera pardus japonensis). Mitochond. DNA 27(2): 1167-1168.

Durant, S.M., S. Bashir, T. Maddox and M.K. Laurenson (2007). Relating long-term studies to conservation practice: the case of the Serengeti Cheetah Project. Conserv. Biol. 21(3): 602-611.

Estes, J.A., J. Terborgh, J.S. Brashares, M.E. Power, J. Berger, W.J. Bond, S.R. Carpenter, T.E. Essington, R.D. Holt, J.B.C. Jackson, R.J. Marquis, L. Oksanen, T. Oksanen, R.T. Paine, E.K. Pikitch, W.J. Ripple, S.A. Sandin, M. Scheffer, T.W. Schoener, J.B Shurin, A.R.E. Sinclair, M.E. Soulé, R. Virtanen and D.A. Wardle (2011). Trophic downgrading of planet Earth. Science 333(6040): 301-306.

Farhadinia, M.S., H. Farahmand, A. Gavashelishvili, M. Kaboli, M. Karami, B. Khalili and S. Montazamy (2015). Molecular and craniological analysis of leopard, Panthera pardus (Carnivora: Felidae) in Iran: support for a monophyletic clade in Western Asia. Biol. J. Linn. Soc. 114(4):721-736.

Farris, Z.J., B.D. Gerber, K. Valenta, R. Rafaliarison, J.C. Razafimahaimodison, E. Larney and C.A. Chapman (2017). Threats to a rainforest carnivore community: A multi-year assessment of occupancy and co-occurrence in Madagascar. Biol. Conserv. 210(1): 116-124.

Ford, A. T. (2017). Opportunities and challenges for the study and conservation of large carnivores. Food Webs 12:107-109.

Gao, E., D. Hu, Z. Wang and Q. Bai (2007). An investigation of Leopards in Liupan Mountain Nature Reserve. For. Res. Manag. 1: 80-2. [In Chinese with English abstract].

Getachew, T. (2012). Biodiversity hotspots: pitfalls and prospects. IBC News Letter 1: 14-16.

Gray, J.E. (1862). Description of some New Species of Mammalia. Proc. Zool. Soc. Lond. 30(1): 261263.

Grumbine, R.E. (2007). China's emergence and the prospects for global sustainability. BioScience 57(3): 249-255. 
Han, S., Y. Guan, H. Dou, H. Yang, M. Yao, J. Ge and L. Feng (2019).Comparison of the faecal microbiota of two free-ranging Chinese subspecies of the leopard (Panthera pardus) using high-throughput sequencing. PeerJ 7 e6684.

Hayward, M.W., G.I. Kerley, J. Adendorff, L. C. Moolman, J. O'brien, A. Sholto-Douglas, C. Bissett, L.C. Moolman, P. Bean, A. Fogarty, D. Howarth, R. Slater and G.I.H. Kerley (2007). The reintroduction of large carnivores to the Eastern Cape, South Africa: an assessment. Oryx 41(2): 205-214.

Henle, K., K.F. Davies, M. Kleyer, C. Margules, and J. Settele (2004). Predictors of species sensitivity to fragmentation. Biodivers. Conserv. 13(1): 207-251.

HLJTV News (2019). Hebei Pingquan finds North Chinese Leopard Again: http://www.hljtv.com/news/folder360/2019-0828/698820.shtml. [Accessed 28 August 2019, in Chinese]

Hou, D. (2012). Leopard found in Jiaozuo. - Jiaozuo Yearbook 230-240. [In Chinese with English abstract].

Hua, Y., K. Vitekere, J. Wang, M. Zhu, M. Zaman and G. Jiang (2020). Coexistence of sympatric carnivores in a relatively homogenous landscape and the effects of environmental factors on site occupation. Ann. Zool. Fennici 57(1-6): 47-58.

Islam, M.Z., A. Boug, A. As-Shehri and M. Al Jaid (2014). Poisoning of endangered Arabian leopard in Saudi Arabia and its conservation efforts. Cat News Special 60:16-17.

Jackson, P. and K. Nowell (2008). Panthera pardus orientalis. In: The IUCN Red List of Threatened Species http://www.iucnredlist.org [accessed 20 August 2019].

Jacobson, A.P., P. Gerngross, J.R. Lemeris, Jr, R.F. Schoonover, C. Anco, C. Breitenmoser-Würsten, S.M. Durant, M.S. Farhadiniam, P. Heschel, J.F. Kamler, A. Laguardia, S. Rostro-Garcia, A.B. Stein and L. Dollar (2016). Leopard (Panthera pardus) status, distribution, and the research efforts across its range. PeerJ, 4, e1974.

Jianjun, D., L. Bingxu, W. Hengrui, G. Ling, Y. Zhixiang, W. Hongyong and L. Hongjian (2018). Breeding of captive North Chinese leopard. J. Henan For. Sci. Tech. 38(1): 52-53. [In Chinese].

Jiping, S. (2010). Mine safety monitoring and control technology and system. Coal. Sci. Technol. 38(10): 1-4.

Kitchener, A.C., C. Breitenmoser, E. Eizirik, A. Gentry, L. Werdelin, A. Wilting N. Yamaguchi, A.V. Abramov, P. Christiansen, C.A. Driscoll, W. Duckworth, W.E Johnson, S. Luo, E. Meijaard, P.O. Donoghue, J. Sanderson, K. Seymour,
M.W. Bruford, C. Groves, M. Hoffmann, K. Nowell, Z. Timmons and S.S. Tobe (2017). A revised taxonomy of the Felidae: The final report of the Cat Classification Task Force of the IUCN Cat Specialist Group. Cat News 1-80.

Kittle, A. and A. Watson (2008). Panthera pardus kotiya. The IUCN Red List of Threatened Species: http://www.iucnredlist.org [accessed 20 August 2019].

Konbini News (2017). French Zoo welcomes birth of rare North Chinese leopard: https://www.konbini.com/en/. [Accessed 22 August 2019].

Kuhn, B.F. (2014). A preliminary assessment of the carnivore community outside Johannesburg, South Africa. S. Afr. J. Wildl. Res. 44(1): 95-98.

Laguardia, A. (2015). Distribution, status and monitoring strategies of the leopard Panthera pardus in China. Ph.D. thesis (unpublished). Dptt. Forestry, Forest. Univ., Beijing.

Laguardia, A., J.F. Kamler, S. Li, C. Zhang, Z. Zhou and K. Shi (2015). The current distribution and status of leopards Panthera pardus in China. Oryx 51(1): 153-159.

Li L. (2016). Rare North Chinese Leopard sits on Taihang Mountains waiting for a road back to Beijing. Beij. Sc. Tech. News 1-4. [In Chinese].

Li, J., H. Yin, D. Wang, Z. Jiagong and Z. Lu (2013). Human-snow leopard conflicts in the Sanjiangyuan region of the Tibetan Plateau. Biol. Conserv. 166: 118-123.

Linkie, M., G. Chapron, D.J. Martyr, J. Holden and N. Leader-Williams (2006). Assessing the viability of tiger subpopulations in a fragmented landscape. J. App. Ecol. 43(3): 576-586.

Linnell, J.D.C, J.E. Swenson and R. Andersen (2001). Predators and people: conservation of large carnivores is possible at high human densities if management policy is favourable. Anim. Conserv. 4(4): 345-349.

Liu W. D. Hu and E. Gao (2007a). Surviving Status of Leopard (Panthera pardus) in Gansu Province. Sich. Journ. Zool. 36(8):86-88. [In Chinese with English abstract]

Liu, W. E. Gao and D. Hu (2007b). The distribution of Leopard Panthera pardus) in Zhejiang Province. Special Wild Economic Animal and Plant Research 3: 43-45. [In Chinese].

Lu, J., D. Hu and L. Yang (2010). Legal status and conservation of cat species in China. Cat News Special 5: 5-6.

MacDonald, D. and A. Loveridge (2010). The biology and conservation of wild felids. 1st Ed. Oxford University Press; New York. 23p

MacKinnon, J. (2002). Status of Biodiversity in AsiaICEM. In: Carew-Reid, J. (ed) Biodiversity 
Planning in Asia, Gland, Switzerland and Cambridge.

Mallon, D., P. Weinberg and N. Kopaliani (2007). Status of the prey species of the leopard in the Caucasus. Cat News Special 2: 22-27.

Mallon, D.P., U. Breitenmoser and J.A. Khan (2008). Panthera pardus nimr. In: The IUCN Red List of Threatened Species: http://www.iucnredlist.org [accessed 16 August 2019].

Ministry of Environment Protection of the People's Republic of China (2011). China National Biodiversity Conservation Strategy and Action Plan.

Minqi, H. (2018). North China Leopard: Growing Quietly in Ziwuling. China Acad. J. Elect. Pub. 1-2. [In Chinese].

Miththapala, S., J. Seidensticker and S.J. O'Brien (1996). Phylogeographic sub-species recognition in leopards (Panthera pardus): molecular genetic variation. Conserv. Biol. 10(4): 1115-1132.

Mongabay News (2017). A spotty revival amid decline for China's endemic leopards: https://news.mongabay.com/2017/07/a-spottyrevival-amid-decline-for-chinas-endemicleopards/ [accessed 14 June 2019].

Mwakatobe, A., J. Nyahongo and E. Røskaft (2013) Livestock depredation by carnivores in the Serengeti ecosystem, Tanzania. Env. Nat. Res. Research 3(4): 46-57.

Myers, N. (1976). The Leopard Panthera pardus in Africa. IUCN Monograph Morges, Switzerland.

Naufal, Z., L. Zhiwen, L. Zhu, O. Gu, D. Zhou, T. McDonald, L.Y. He, L. Mitchell, A. Ren, H. Zhu, R. Finnell and K.C. Donnelly (2010). Biomarkers of exposure to combustion byproducts in a human population in Shanxi, China. J. Expo. Sci. Environ. Epidemiol. 20(4): 310319.

NBC News (2009). Two Chinese leopard cubs born in Paris zoo: http://www.nbcnews.com/id/28750845/ns/techn ology_and_science-science/t/two-chineseleopard-cubs-born-paris-zoo/\#.XV5Sm-MzbIU [accessed 14 August 2019].

Noss, R.F., H.B. Quigley, M.G. Hornocker, T. Merrill and P.C. Paquet (1996). Conservation biology and carnivore conservation in the Rocky Mountains. Conserv. Biol. 10(4): 949-963.

Nowell, K. and P. Jackson (1995). New Red List Categories for Wild Cats. Cat News Special 23: 21-27.

Nowell, K. and P. Jackson (1996). Wild Cats: Status Survey and Conservation Action Plan. IUCN/SSC, Cat Specialist Group Gland, Switzerland.
Nowell, K., J. Li, M. Paltsyn and R.K. Sharma (2016). An ounce of prevention: snow leopard crime revisited. TRAFFIC.

O'Brien, S.J. and E. Mayr (1991). Bureaucratic mischief: recognizing endangered species and subspecies. Science 251(4998): 1187-1188.

Odden, M., V. Athreya, S. Rattan and J.D.C. Linnell (2014). Adaptable neighbours: movement patterns of GPS-collared leopards in human dominated landscapes in India. PLoS ONE $9 \mathrm{e} 112044$.

Oswell, A.H. (2010). The Big Cat Trade in Myanmar and Thailand, Southeast Asia. TRAFFIC.

Perez, I., E. Geffen and O. Mokady (2006). Critically endangered Arabian leopards Panthera pardus nimr in Israel: estimating population parameters using molecular scatology. Oryx 40(3): 295-301.

Pocock, R.I. (1930). The panthers and ounces of Asia. J Bombay Nat. Hist. Soc. 63: 307-336.

Ran, J. and H. Chen (2002). The wild leopard and its protection in Guizhou province. Guizhou Forestry Science and Technology 30: 24-24. [In Chinese].

Ray, J.C., L. Hunter and J. Zigouris (2005). Setting Conservation and Research Priorities for Larger African Carnivores. 1st Ed. Wildlife Conservation Society; New York. 213p

Raza, R.H., D.S. Chauhan, M.K.S. Pasha and S. Sinha (2012). Illuminating the Blind Spot: A Study on Illegal Trade in Leopard Parts in India (20012010). TRAFFIC India/WWF, New Delhi.

Riordan, P. and K. Shi (2016). China: current state of snow leopard conservation in China. 1st Ed. Academic Press; Beijing. 531p

Ripple, W.J., J.A. Estes, R.L. Beschta, C.C. Wilmers, E.G. Ritchie, M. Hebblewhite, J. Berger, B. Elmhagen, M. Letnic and M.P. Nelson (2014). Status and ecological effects of the world's largest carnivores. Science 343(6167): 151-163.

Rodgers, T. W. and J.E. Janečka (2013). Applications and techniques for non-invasive faecal genetics research in felid conservation. Eur. J. Wild Res. 59(1): 1-16.

Rostro-García, S., J.F. Kamler, E. Ash, G.R. Clements, L. Gibson, A.J. Lynam, R. McEwing, H. Naing and S. Paglia (2016). Endangered leopards: range collapse of the Indochinese leopard (Panthera pardus delacouri) in Southeast Asia. Biol Conserv.201: 293-300.

Sears, S.V. (2018). Leopards in China: the wild card. J. Creat. Sust. 1-5.

Shoemaker, A.H. (1978). Status of rare leopards in captivity. Carnivore 1: 95-103.

Shoemaker, A.H. (1983). Population dynamics of pedigree leopards, Panthera pardus ssp, in captivity. Zoo Biol. 2(2): 79-91. 
Shoemaker, A.H. (1993). The status of the leopard, Panthera pardus, in nature: a country by country analysis. 1st Ed. Riverbanks Zoological Park; Columbia. 213p

Smith, A.T. and Y. Xie (2008). A Guide to the Mammals of China. 1st Ed. Princeton University Press; New Jersey (USA). $544 \mathrm{p}$

Sohu News (2003). Leopard confronted people for five hours and captured in Fengxiang County, Shaanxi, thousands of onlookers saw it: http://news.sohu.com/70/82/news205928270.sht $\mathrm{ml}$ [accessed 25 August 2019, in Chinese]

Sohu News (2006). Wild leopard trespassed into people's home in Shaanxi: http://news.sohu.com/20060304/n242121450.sht $\mathrm{ml}$ [accessed August 20 2019, in Chinese]

Song, D. (2012). North Chinese Leopard lives only in China. Forest and Humankind 8: 26-33. [In Chinese].

Song, D. (2015). North Chinese Leopard in Taihang Mountain. Forest and Humankind 3: 72-79. [In Chinese].

Song, D. (2016). Discovery of the North China Leopard by Infrared Camera. Forest and Humankind 11: 146-153[In Chinese].

Song, D. (2018). We will go together with them. Forest and Humankind 1:66-71. [In Chinese].

Song, D. and C. Yuelong (2019). The Wilderness of the North Chinese Leopard. Forest and humankind 1: 80-87. [In Chinese].

Song, D. (2019). North China Leopard: China's surviving forest kings. Forest and humankind 1: 21-35. [In Chinese].

Song, D., B. Wang, J. Jiang, S. Wan, S. Cui, T. Wang and L. Feng (2014). Using camera traps to monitor a North Chinese leopard (Panthera pardus japonesis) population and their main ungulate prey. Biodiver. Sci. 22: 733-736. [In Chinese with English abstract].

Standaert, M. (2018). China Creates a Refuge for the Imperiled Siberian Tiger: In New Park. Available at https://e360.yale.edu/features/china-carves-outa-park-for-the-imperiled-siberian-tiger [accessed 8 June 2019].

Steffen, W., A. Persson, L. Deutsch, J. Zalasiewicz, M. Williams, K. Richardson, C. Crumley, P. Crutzen, C. Folke, L. Gordon, M. Molina, V. Ramanathan, J. Rockstrom, M. Scheffer, H.J. Schellnhuber and U. Svedin (2011). The Anthropocene: From global change to planetary stewardship. Ambio, 40(7): 739-761.

Stein, A.B. and V. Hayssen (2013). Panthera pardus (Carnivora: Felidae). Mamm. Species 47(900): 30-48.
Stein, A.B., V. Athreya, P. Gerngross, G. Balme, P. Henschel, U. Karanth, D. Miquelle, S. Rostro, J.F. Kamler and A. Laguardia (2016). Panthera pardus. In: The IUCN Red List of Threatened Species.

Sung, W. (1998). China red data book of endangered animals. Science Press; Beijing (China).

Sunquist, M. and F. Sunquist (2017). Wild cats of the world. 2nd Ed. University of Chicago press; Chicago. 452p

Sutherland, W.J., A.S. Pullin, P.M. Dolman and T.M. Knight (2004). The need for evidence-based conservation. Trends Ecol. Evol. 19(6): 305-308.

Tittensor, D.P., M. Walpole, S.L. Hill, D.G. Boyce, G.L. Britten, N.D. Burgess, S.H. Butchart, P.W. Leadley, E.C. Regan and R. Alkemade (2014). A mid-term analysis of progress toward international biodiversity targets. Science 346(6206): 241-244.

Treves, A. and K.U. Karanth (2003). Human-carnivore conflict and perspectives on carnivore management worldwide. Conserv. Biol. 17(6): 1491-1499

Uphyrkina, O., D. Miquelle, H. Quigley, C. Driscoll and S.J. O'Brien (2002). Conservation genetics of the far eastern leopard (Panthera pardus orientalis). J. Hered. 93(5): 303-311.

Uphyrkina, O., W.E., Johnson, H. Quigley, D. Miquelle, L. Marker, M. Bush and S.J. O'Brien (2001). Phylogenetics, genome diversity and origin of modern leopard, Panthera pardus. Mol. Ecol. 10(11): 2617-2633.

Vitekere, K., J. Wang, H. Karanja, K.T. Consolée, G. Jiang, and Y. Hua (2020). Dynamic in Species Estimates of Carnivores (Leopard Cat, Red Fox, and North Chinese Leopard): A Multi-Year Assessment of Occupancy and Coexistence in the Tieqiaoshan Nature Reserve, Shanxi Province, China. Animals 10(8), 1333.

Wang, H., J. Lu, F. Tang, J. Liu and J. Kong (2008). Resources status and protection of Panthera pardus in Taihang Mountain National Reserve, Jiyuan, China. J. Henan Forestry Science and Technology 28: 94-95. [In Chinese with English abstract].

Wang, S. and Y. Xie (2004). China Species Red List. Higher Education Press, Beijing.

Wang, T., L. Feng, P. Mou, J. Wu, J.L. Smith, W. Xiao, H.,Yang, H.,Dou, X.,Zhao, Y. Cheng, B. Zhou, H. Wu, L. Zhang, Y. Tian, Q. Guo, X. Kou, X. Han, D.G. Miquelle, C.D. Oliver, R. Xu and J. Ge (2016). Amur tigers and leopards returning to China: direct evidence and a landscape conservation plan. Landsc. Ecol. 31(3): 491-503.

Wei, Y.W., D.P. Yu, B.J. Lewis, L. Zhou, W. Zhou, X. Fang, W. Zhao, S. Wu and L. Dai (2014). Forest 
carbon storage and tree carbon pool dynamics under natural forest protection program in Northeastern China. Chin. Geogr. Sci. 24(4): 397-405.

Wei, L., C. Wei, L. Jinbang and S. Hongwei (2019). The abundance of the North Chinese Leopard in captivity. Dynamic 28. [In Chinese].

Wildfact News (2017). Leopards of Northern China: https://wildfact.com/forum/topic-north-chineseleopard-panthera-pardus-japonensis [accessed 16 August 2019].

Williams, S.T., K.S. Williams, B.P. Lewis and R.A. Hill (2017). Population dynamics and threats to an apex predator outside protected areas: implications for carnivore management. Royal Soc. Open Sci. 4(4): 161090.

Woodroffe, R. (2000). Predators and people: using human densities to interpret declines of large carnivores. Anim. Conserv. 3(2): 165-173.

Xiaomin, G. (2019). Assessment on Habitat Suitability for Panthera Pardus Fontanierii in Tieqiao Mountain Nature reserve based on maxent model. Shanxi forestry science and technology 48: 1-3. [In Chinese with English abstract].
Xie, Y., X. Gan and W. Yang (2014). Strengthening the legal basis for designating and managing protected areas in China. J. Int. Wildl. Law. Pol. 17(3): 115-129.

$\mathrm{Xu}$, J. and D.R. Melick (2007). Rethinking the effectiveness of public protected areas in southwestern China. Conserv. Biol. 21(2): 318328.

Xu, H., X. Tang, J. Liu, H. Ding, J. Wu, M. Zhang, Q. Yang, L. Cai, H. Zhao and Y. Liu (2009). China's progress toward the significant reduction of the rate of biodiversity loss. BioScience 59(10): 843-852.

Yuelong, C. (2019).Two leopard prints are not the same. How to identify the North Chinese Leopard Forest and Humankind 1: 74-79. [In Chinese].

Yuli, H. (2018). Population Quantity Investigation of Panthera Pardus Fontanierii of Tieqiao Mountain in Shanxi. Shanxi forestry science and technology 47: 1-2. [In Chinese with English abstract].

Zhou, Y. (2017). A Suitability and Connectivity Analysis of North Chinese Leopard: take the leopard home. Tufts University Press, Massachusetts. 